\title{
Extracellular biosynthesis of silver nanoparticles from Cyanobacteria.
}

\author{
Sarah Al Rashed, Samiha Al Shehri, Nadine MS Moubayed* \\ Botany and Microbiology Department, Science College, Girls Campus, King Saud University, Riyadh, Kingdom of \\ Saudi Arabia
}

\begin{abstract}
The field of nanotechnology is being now extensively studied by researchers particularly synthesis of nanoparticles with non-toxic, environmentally benign techniques and using mainly microorganisms including bacteria, fungi and algae. These bio-synthesized nanoparticles are aimed to be used as alternatives to the medical agents; however, their activity depends on their size, morphology, distribution and the source of bio synthesis. In this study silver nanoparticles were synthesized from three types of Cyanobacteria naming Nostoc sp., Scytonema sp. and Phormidium sp. Higher antibacterial activity was obtained with Scytonema Nanoparticles (NP) extracts against MRSA followed by Phormidium sp. compared to other algal NP extracts against Staphylococcus aureus, E. coli and Pseudomonas aeruginosa. Chemical analysis of the studied algal NP extracts revealed higher peaks at $3278 \mathrm{~cm}^{-1}$ and $3262 \mathrm{~cm}^{-1}$ for Phormidium and Nostoc algal species, indicating the presence of NP particles to which the antibacterial activity is being attributed.
\end{abstract}

Keywords: Scytonema, Phormidium, Nostoc, Cyanobacteria, Antibacterial, Nanoparticles. Abbreviations:

Silver Nanoparticles (AgNPs); Silver Nitrate $\left(\mathrm{AgNO}_{3}\right)$.

Accepted on June 25, 2018

\section{Introduction}

Nanoparticle synthesis particularly from plants and algae nowadays is becoming the booming of most recent scientific research. However, the efficacy of these nanoparticles resides in the methods of synthesis where the biological techniques were found to be more effective than the chemical and the physical ones; it is also and most importantly linked to the type of algae or plants used.

Biological methods for synthesizing nanoparticles have shown better results compared to chemical and physical techniques due to time consumption, slow kinetics [1,2] low cost [3] and most importantly it is more eco-friendly compared to the chemical and physical techniques [4].

Algae used in the biosynthesis of nanoparticles have recently attracted the attention of many scientific researches [2] due to their rapid growth, to their biomass formation and to their different biological activities by nature. Extensive work has been conducted on different types of algae mainly Spirulina platensis [5-7] for the bio-synthesis of nanoparticles. So far, Mubarak et al., Mahdieh et al. and Pal [5-7] have used Cyanobacteria for the synthesis of silver and gold nanoparticles; they reported good antibacterial activity against some human pathogenic bacteria. Thus taking into consideration the importance of algae, two types of Cyanobacteria were investigated in this study namely Nostoc sp. and Scytonema sp. together with Phormidium sp. for the biosynthesis of Silver Nanoparticles (AgNPs). The algal AgNPs were determined using the FTIR spectrophotometer and the transmission electron microscope, and then tested in vitro against some gram positive and gram negative bacteria.

\section{Materials and Methods}

\section{Algal samples growth and collection}

Nostoc, Scytonema and Phormidium sp. were obtained from King Saud University, Botany Department, Riyadh, and KSA. They were grown at the botany department female section in a BG 11 medium (pH 7) [8].

\section{Preparation of AgNP extracts}

All algal samples were washed with sterile distilled water and kept to dry at room temperature. Dried samples were then ground into powder to be used for the synthesis of AgNPs when mixed to $1 \mathrm{mM}$ silver nitrate solution prepared in dark reagent bottle $(1 \mathrm{mg} / 2 \mathrm{ml})$ [9]. Extracts were kept in a shaking incubator at $140 \mathrm{rpm}$ and $30^{\circ} \mathrm{C}$ until a color change occurred from pale yellow to dark brown indicating the synthesis of AgNPs. A small amount of $\mathrm{AgNO}_{3}$ solution without algal samples was kept as a negative control. 


\section{Bacterial strains tested}

The bacterial strains tested in the present work were all obtained from the Microbiology department, King Saud University and were as follows Staphylococcus aureus ATCC 25923, Methicillin Resistant Staphylococcus aureus (MRSA) ATCC3345 as gram positive bacteria whereas the gram negative bacteria used were namely E. coli ATCC 25966 and Pseudomonas aeruginosa ATCC 27853.

All bacterial strains were grown on nutrient agar plates and then fresh bacterial suspensions of 0.5 MacFarland turbidity were prepared in $5 \mathrm{ml}$ sterile nutrient broth test tubes.

\section{Antibacterial assay}

In vitro antibacterial activity was performed using agar well diffusion technique [10], where Mueller Hinton plates were inoculated first with the freshly prepared bacterial suspension separately using sterile cotton swabs; then the plates were perforated using sterile cork borer of $6 \mathrm{~mm}$ diameter into four equidistant wells to be filled with $70 \mu \mathrm{l}$ of each of the algal $\mathrm{Ag}$ NPs extracts correspondingly and the negative control $\mathrm{AgNO}_{3}$ solution. Plates were incubated at $37^{\circ} \mathrm{C}$ for $24 \mathrm{~h}$. The antibacterial activity was determined by measuring the inhibition zone around each well respectively and average of 3 repeated experiments were obtained. Data were compared to positive control standard antibiotic discs and to the negative control $\mathrm{AgNO}_{3}$ solution.

\section{FTIR analysis}

Chemical analysis using the FTIR spectrophotometer was performed on a Perkin-Elmer FTIR spectrophotometer (USA) in the diffuse reflectance mode at a resolution of $4 \mathrm{~cm}^{-1}$ in $\mathrm{KBr}$ pellets to reveal the presence of AgNPs biosynthesis using the algal samples in study. Silver nanoparticles are observed at $3000-4000 \mathrm{~cm}^{-1}$ absorption.

\section{Transmission Electron microscope TEM}

$5 \mu \mathrm{l}$ of Phormidium AgNPs extract were placed on a carboncoated copper grid. Grids were dried under infrared lamp and inspected in TEM microscope (Joelle, Japan), operated at an accelerating voltage of $100 \mathrm{kV}$. All particles showed a circular shape and an average size of AgNPs (5-10 nm).

\section{Results and Discussion}

The Cyanobacteria filtrates when added to $1 \mathrm{mM} \mathrm{AgNO}_{3}$ changed in color from pale yellow to dark brown indicating the biosynthesis of silver nanoparticles which were further revealed by the FTIR analysis which indicated very strong absorption peaks of silver nanoparticles at 3278 and $3262 \mathrm{~cm}^{-1}$ from Phormidium, Scytonema and Nostoc respectively. These bands were assigned to the stretching vibrations of primary and secondary amines respectively. The corresponding bending vibrations were seen at 1628.63 and $1634 \mathrm{~cm}^{-1}$. The band observed at $1317.48 \mathrm{~cm}^{-1}$ can be assigned to $\mathrm{C}-\mathrm{N}$ stretching vibration of amines. In Agreement with our findings, Mubarak et al. [5] confirmed the presence of a protein shell which is responsible for the nanoparticles biosynthesis and considered as the stabilizing agent surrounding the AgNPs and to which this effective antibacterial activity could be correlated (Figures $1-3)$.

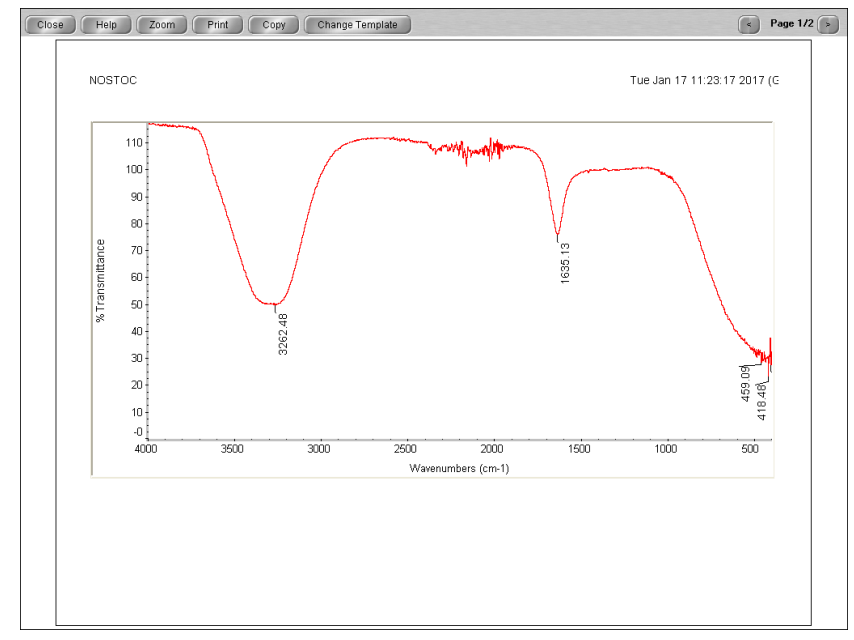

Figure 1. FTIR spectrum for Nostoc indicating the presence of AgNPS at $3262 \mathrm{~cm}^{-1}$.

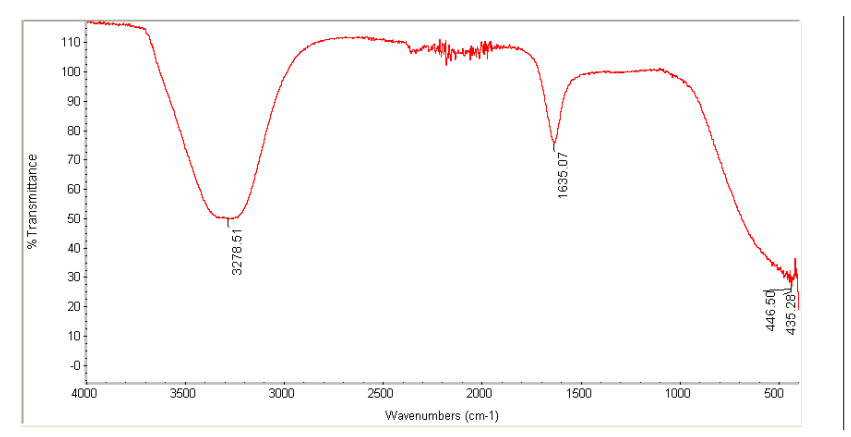

Figure 2. Phormidium FTIR spectrum revealing the presence of AgNPs at $3278 \mathrm{~cm}^{-1}$.

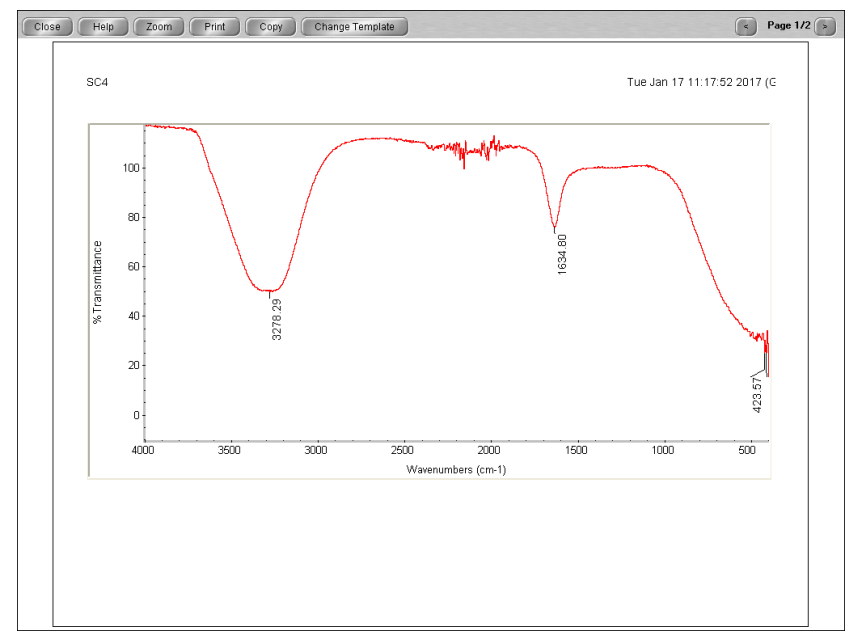

Figure 3. Scytonema AgNPs revealed at $3278 \mathrm{~cm}^{-1}$.

Previous studies have demonstrated that the antimicrobial nature of AgNPs to be size [11] and shape dependent [12] where smaller nanoparticles displayed better antimicrobial 
activity TEM microscope was also applied in this study to measure and determine both the size and the morphology of the synthesized nanoparticles. Data showed that the size of the nanoparticles synthesized by the Phormidium $s p$. ranged between 5-10 nm, moreover all these particles were spherical in shape (Figure 4). Following the chemical composition analysis and the microscopic observation, the antibacterial activity of each of the algal nanoparticles extracts was performed against some gram negative and gram positive human pathogenic bacteria (Figure 4).

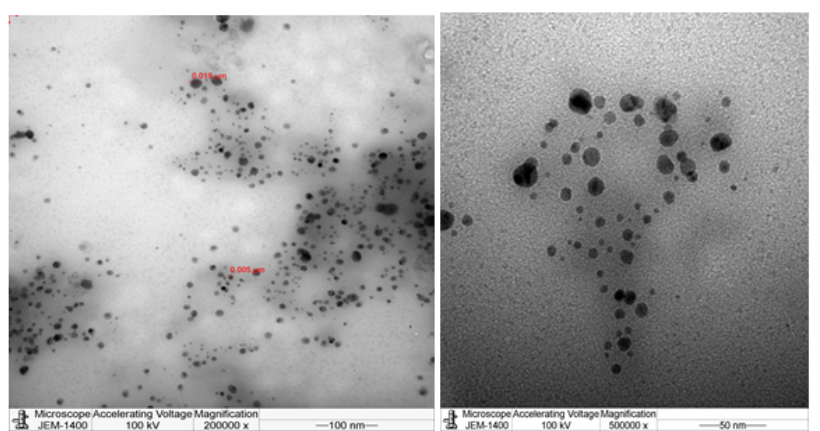

Figure 4. Phormidium TEM showing synthesized AgNPs of spherical shape and a size ranging between 5-10 $\mathrm{nm}$.

Data obtained from this study showed greater antibacterial activity with Scytonema sp. silver extract followed by
Phormidium sp. extract mainly against MRSA (12 $\mathrm{mm}$ and $11.5 \mathrm{~mm}$ ) correspondingly, Pseudomonas aeruginosa, E. coli showed on the other hand an inhibition zone diameter ranging between 8 and $10 \mathrm{~mm}$ with Phormidium sp. and Scytonema sp. Nostoc $s p$. has the least antibacterial activity against MRSA (2 $\mathrm{mm})$ but higher effect against Staphylococcus aureus $(10 \mathrm{~mm})$ compared to the other algal species nanoparticles extracts being studied, in agreement with [13,14] who reported that AgNPs have showed antibacterial activities against gram positive and gram negative bacteria. However, this slight difference in the antibacterial activity between the three algal samples in study (Table 1) could be explained by the aggregation, the size of the synthesized nanoparticles which may be correlated to the Surface Area and Volume (SA/V) ratio. As the size of AgNPs decreases the SA/V ratio for individual particles increases and the relative particle concentration also increases $[15,16]$ thereby enhancing the antibacterial activity. Furthermore, the type of algal species may as well attribute to synthesizing nanoparticles with variable shapes and sizes and hence with variable potency of antibacterial activity [17]. As a conclusion, algal samples could be considered a good source of biosynthesized AgNPs applied in different therapeutic and environmental fields.

Table 1. Average inhibition zone AgNPs synthesized by different algal species measured in mm compared to the silver nitrate AgNO $\mathrm{O}_{3}$ (negative control).

\begin{tabular}{|c|c|c|c|c|}
\hline \multicolumn{5}{|c|}{ Average inhibition zone of $\mathrm{Ag}$ particles synthesized measured in $\mathrm{mm}$} \\
\hline Microorganisms & Phormidium & Nostoc & Scytonema & $\mathrm{AgNO}_{3}$ (Negative control) \\
\hline Staphylococcus aureus ATCC (25923) & 9 & 10 & 7 & 9 \\
\hline MRSA ATCC (12498) & 11.5 & 2 & 12 & 10 \\
\hline Pseudomonas aeruginosa ATCC (27853) & 8 & 9 & 9 & 11.5 \\
\hline E. coli ATCC (25966) & 10 & 9 & 9.5 & 10 \\
\hline
\end{tabular}

\section{Conclusion}

The extracellular biological synthesis of AgNPs from Cyanobacteria can be considered as one of the best techniques in the nanotechnology field since it is time and cost saving. A potent antibacterial activity was attributed to the size, shape and amount of the AgNPs synthesized and mostly to the type of the algal species; however, more intracellular investigations should be involved to determine the mechanism of action of these nanoparticles.

\section{Acknowledgment}

This research project was supported by a grant from the "Research Center of the Center for Female Scientific and Medical Colleges", Deanship of Scientific Research, King Saud University.

\section{References}

1. Vijayaraghavan K, Nalini SPK. Biotemplates in the green synthesis of silver nanoparticles. Biotechnol J 2010; 5: 1098-1110.

2. Husain S, Sardar M, Tasneem F. Screening of cyanobacterial extracts for synthesis of silver nanoparticles. World J Microbiol Biotechnol 2015; 6: 1-9.

3. Tan S, Erol M, Attygalle A, Du H. Synthesis of positively charged silver nanoparticles via photoreduction of AgNO3 in branched polyethyleneimine/HEPES solutions. Langmuir 2007; 23: 9836-9843.

4. Umer A. Selection of suitable method for the synthesis of copper nanoparticles. NANO Brief Rep Rev World Sci Publ Comp 2012; 7: 1-18.

5. Mubarak DA, Sasikala M, Gunasekaran M, Thajuddin N. Biosynthesis and characterization of silver nanoparticles 
using marine cyanobacterium, Oscillatoria willei NTDM01. Dig J Nanomat Biostr 2011; 6: 385-390.

6. Mahdieh M, Zolanvari A, Azimee AS, Mahdieh M. Green biosynthesis of silver nanoparticles by Spirulina platensis. Sci Irani 2012; 19: 926-929.

7. Ahmed EA, Abdel Hafez EH, Ismail AFM, Elsonbaty SM, Abbas HS, Salah El Din RA. Biosynthesis of silver nanoparticles by Spirulina platensis AND Nostoc sp. Global Adv Res J Microbiol 2015; 4: 36-49.

8. Ray S, Bagchi SN. Nutrients and $\mathrm{pH}$ regulate algicide accumulation in cultures of the Cyanobacterium Oscillatoria laetevirens. New Phytologist 2001; 149: 455-460.

9. Sinha SN, Paul D, Halder N, Sengupta D, Patra SK. Green synthesis of silver nanoparticles using fresh water green alga Pithophora oedogonia (Mont.) Wittrock and evaluation of their antibacterial activity. Appl Nanosci 2015; 5: 703-709.

10. Patel V, Berthold D, Puranik P, Gantar M. Screening of Cyanobacteria and microalgae for their ability to synthesize silver nanoparticles with antibacterial activity. Biotechnol Rep 2015; 5: 112-119.

11. Morones JR, Elechiguerra JL, Camacho A, Holt K, Kouri JB, RamIrez JT, Yacaman MJ. the bactericidal effect of silver nanoparticles. Nanotechnology 2005; 16: 2346-2353.

12. Pal S, Tak YK, Song JM. Does the antibacterial activity of silver nanoparticles depends on the shape of the nanoparticles? a study of the gram-negative bacterium Escherichia coli. Appl Enviorn Microbiol 2007; 73: 1712-1720.
13. Theivasanthi T, Alagar M. Antibacterial studies of silver nanoarticles. Gene Phys Cornell Univ Lib 2011.

14. Thomas R, Viswan A, Mathew J, Radhakrishnan EK. Evaluation of antibacterial activity of silver nanoparticles synthesized by a novel strain of marine Pseudomonas $s p$. Nano Biomed Eng 2012; 9: 139-143.

15. Samberg ME, Orndorff PE, Monteiro-Riviere NA. Antibacterial efficacy of silver nanoparticles of different sizes, surface conditions and synthesis methods. Nanotoxicology 2011; 5: 244-253.

16. Lok CN, Ho CM, Chen R, He QY, Yu WY, Sun H, Tam PK, Chiu JF, Che CM. Silver nanoparticles: partial oxidation and antibacterial activities. J Biol Inorg Chem 2007; 12: 527-534.

17. Rai MK, Deshmukh SD, Ingle AP, Gade AK. Silver nanoparticles: the powerful nano-weapon against multidrug-resistant bacteria. J Appl Microbiol 2012; 112: 841-852.

\section{*Correspondence to}

Nadine Moubayed

Botany and Microbiology Department

Science College

Girls Campus

King Saud University

Kingdom of Saudi Arabia 